\title{
RANCANG BANGUN ALAT PENGIRIS BAWANG MERAH KAPASITAS 46 KG/JAM
}

\author{
Yafid Effendi, Fajar Danuriyanto \\ Program Studi Teknik Mesin, Fakultas Teknik, Universitas Muhammadiyah Tangerang \\ J1. Perintis Kemerdekaan I, No. 33, Cikokol, Tangerang, Banten 15118, Indonesia \\ E-mail :yafid_effendi@yahoo.com dan fajardanuriyanto@gmail.com
}

\begin{abstract}
ABSTRAK
Tanaman bawang merah di Indonesia telah lama diusahakan oleh petani sebagai usaha tani yang bersifat komersil, yang sebagian besar atau seluruh hasil produksinya ditunjukan untuk memenuhi permintaan. Berdasarkan hasil pemantauan Direktoral Jendral Bina Produksi Hortikultura, produksi bawang merah di Indonesia menurut propinsi mengalami fluktuasi yang sangat signifikan selama periode 2009-2013. Dalam pengolahan hasil pertanian banyak pemesinan yang digunakan, diantaranya adalah alat pengiris bawang merah yang digunakan sebagai teknologi yang memudahkan dalam pengolahan bawang merah. Metode yang digunakan adalah studi literatur (kepustakaan), melakukan eksperimen dan melakukan pengamatan tentang alat pengiris bawang merah. Kemudian dilakukan perancangan bentuk dan pembuatan/perangkaian komponen-komponen alat pengiris. Setelah itu, dilakukan pengujian alat dan pengamatan parameter besar daya yang dibutuhkan untuk alat pengiris bawang merah, prinsip kerja alat pengiris bawang merah, dan kapasitas efektif alat pengiris bawang merah. Tujuan penelitian adalah membuat alat pengiris bawang merah yang berdaya kecil dan efektif sehingga dapat mendukung peningkatan hasil produksi irisan bawang merah, yang siap olah (digoreng). Hasil penelitian menunjukkan bahwa alat pengiris bawang merah ini membutuhkan daya sebesar 0,118 Hp untuk mengoperasikannya, dengan prinsip kerja menggunakan piringan berpisau yang akan berputar dan mengiris bawang merah. Kapasitas efektif alat sebesar $46 \mathrm{~kg} / \mathrm{jam}$ dengan putaran pisau pengiris $431 \mathrm{rpm}$, dan tebal irisan $1-1,5 \mathrm{~mm}$.
\end{abstract}

Kata Kunci : Bawang merah, alat pengiris, kapasitas efektif

\section{PENDAHULUAN}

Tanaman bawang merah di Indonesia telah lama diusahakan oleh petani sebagai usaha tani yang bersifat komersil, yang sebagian besar atau seluruh hasil produksinya ditunjukan untuk memenuhi permintaan. Berdasarkan hasil pemantauan Direktoral Jendral Bina Produksi Hortikultura, produksi bawang merah di Indonesia menurut propinsi mengalami fluktuasi yang sangat signifikan selama periode 2009-2013.

Dalam pengolahan hasil pertanian banyak pemesinan yang digunakan, diantaranya adalah alat pengiris bawang merah yang digunakan sebagai teknologi yang memudahkan dalam pengolahan bawang merah. Alat pengiris bawang merah ini diharapkan mendukung peningkatan hasil produksi irisan bawang merah, yang siap olah (digoreng).

Pada saat ini masih banyak alat pengirisan yang berkapasitas besar dan tidak dapat digunakan oleh industri rumahan.
Kelemahan dari alat yang ada dipasaran yaitu tidak seragamnya hasil irisan dan penggunaan listrik yang sangat besar pada alat ini. Pada alat-alat yang terdapat dipasaran menggunakan bahan aluminium pada bagian corong yang dapat mengakibatkan terjadinya kontaminasi pada bahan baku yang diiris dan tidak diperhatikannya sarana untuk membersihkan alat tersebut (Tantan W., 2009).

Dengan adanya kelemahan alat pengiris bawang merah di pasaran saat ini, maka dibutuhkan alat pengiris bawang merah menggunakan motor listrik berdaya kecil sebagai pengerak, menyeragamkan hasil irisan, mempermudah untuk melakukan sanitasi dan memperkecil terjadinya kontaminasi pada bahan baku yang akan diiris, sehingga alat pengiris bawang merah dapat digunakan secara efektif oleh industri rumahan. 


\section{METODE PENELITIAN}

\section{A. Desain Penelitian}

Dalam penelitian ini, metode yang digunakan adalah studi literatur (kepustakaan), melakukan eksperimen dan melakukan pengamatan tentang alat pengiris bawang merah. Kemudian dilakukan perancangan pembuatan /perangkaian komponen-komponen alat pengiris. Setelah itu, dilakukan pengujian alat dan pengamatan parameter. Alat pengiris bawang merah adalah alat yang dirancang untuk mengiris bawang merah dengan menggunakan alat tenaga penggerak otor listrik, dapat dilihat pada gambar.

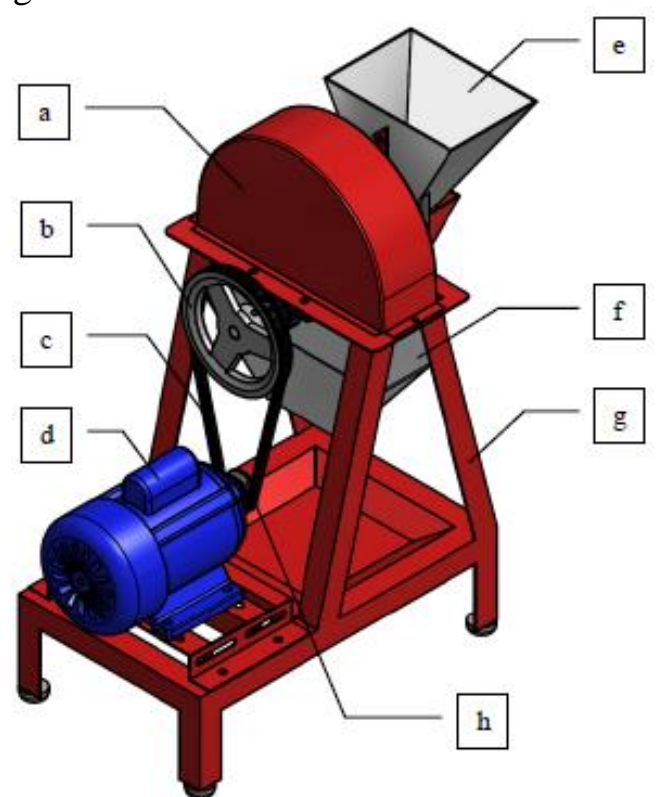

Gambar 1. Komponen Alat Pengiris Bawang Merah

Keterangan:
a. Penutup Pisau
b. Pulley $\emptyset 165,1 \mathrm{~mm}$
c. V-belt
d. Motor
e. Hopper Input
f. Hopper Output
g. Rangka Alat
h. Pulley $\emptyset 50,8 \mathrm{~mm}$

\section{B. Diagram Alir Proses Penelitian}

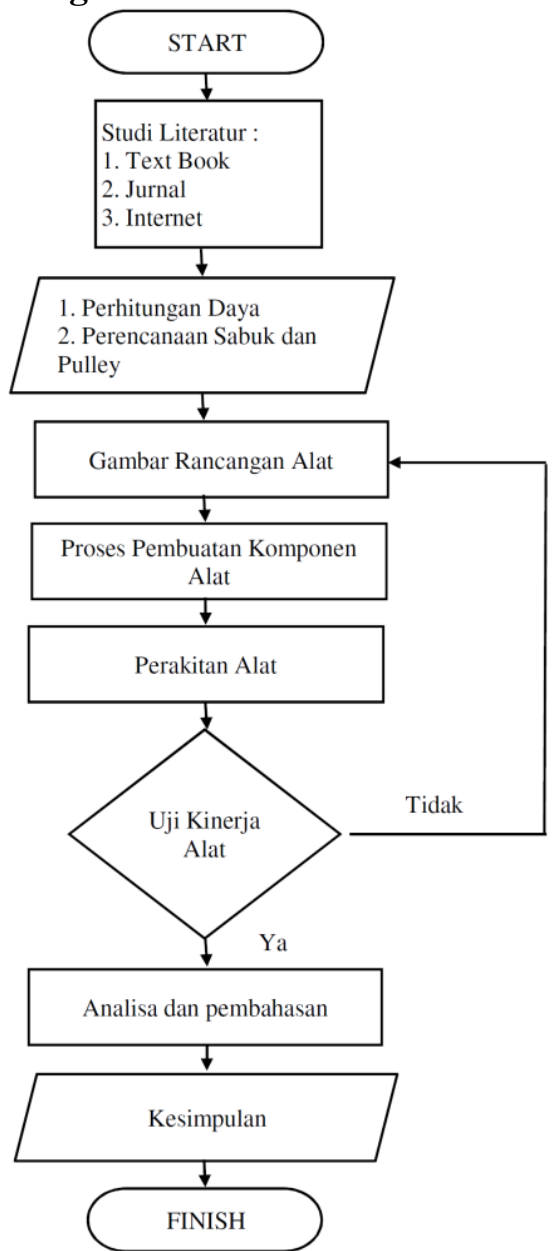

Gambar 2. Diagram Alir Proses Penelitian

\section{Metode Analisa Data}

Berikut adalah rumus untuk mencari harga daya, gaya, torsi, kecepatan putar dan berat:

1. Mencari harga daya $(\mathrm{P})$

Berdasarkan putaran poros, daya dirumuskan:

$$
P=\frac{2 \pi n T}{60}
$$

(Khurmi, R.S, 2005)

Dimana:

$$
\begin{aligned}
& \mathrm{P}: \text { Daya (Watt) } \\
& \mathrm{T}: \text { Torsi (N.m) } \\
& \mathrm{n}: \text { Putaran poros (rpm) }
\end{aligned}
$$

2. Mencari harga gaya $(\mathrm{F})$

Gaya adalah suatu besaran yang menyebabkan benda bergerak, gaya dirumuskan:

$\mathrm{F}=\mathrm{m} \cdot \mathrm{g}\left(\mathrm{N}\right.$ atau $\left.\mathrm{kg} \cdot \mathrm{m} / \mathrm{s}^{2}\right)$

Dimana:

F : Gaya (N atau kg.m/s $\left.\mathrm{s}^{2}\right)$

$\mathrm{m}:$ Massa $(\mathrm{kg})$

$\mathrm{g}$ : Percepatan gravitasi $\left(10 \mathrm{~m} / \mathrm{s}^{2}\right)$ 
3. Mencari harga berat (W)

Berat suatu benda adalah gaya gravitasi yang bekerja pada benda itu, berat dirumuskan:

$\mathrm{W}=\mathrm{m} \cdot \mathrm{g}\left(\mathrm{N}\right.$ atau $\left.\mathrm{kg} \cdot \mathrm{m} / \mathrm{s}^{2}\right)$

Dimana:

$\mathrm{W}$ : Berat $\left(\mathrm{N}\right.$ atau $\left.\mathrm{kg} \cdot \mathrm{m} / \mathrm{s}^{2}\right)$

$\mathrm{m}$ : Massa $(\mathrm{kg})$

$\mathrm{g}$ : Percepatan gravitasi $\left(10 \mathrm{~m} / \mathrm{s}^{2}\right)$

4. Mencari harga torsi $(\mathrm{T})$

Besarnya torsi merupakan hasil perkalian gaya dengan jarak terhadap sumbu, torsi dirumuskan:

$\mathrm{T}=\mathrm{F} . \mathrm{r}$

Diaman :

T : Torsi (N.m)

$\mathrm{F}$ : gaya $(\mathrm{N})$

$\mathrm{R}:$ Jarak terhadap sumbu (m)

5. Menentukan panjang sabuk

$$
L=\pi\left(r_{1}+r_{2}\right)+2 x+\left\{\frac{\left(r_{1}-r_{2}\right)^{2}}{x}\right\}
$$

(Sularso., 1991)

Dimana :

L : Panjang sabuk (mm)

$\mathrm{x}:$ Jarak sumbu poros $(\mathrm{mm})$

$\mathrm{r}_{1}$ : Jari-jari pulley penggerak $(\mathrm{mm})$

$\mathrm{r}_{2}$ : Jari-jari pulley yang digerakkan (mm)

6. Kapasitas kerja alat

Kapasitas Alat $=\frac{\text { Produk yang dihasilkan }}{\text { Waktu }}$.

Dimana :

(Daywin., 2008)

Kapasitas Alat (Kg/jam)

Produk yang dihasilkan $(\mathrm{Kg})$

Waktu (Jam)

\section{HASIL ANALISA DAN PEMBAHASAN}

\section{A. Analisa}

Kebutuhan daya adalah besarnya daya yang digunakan untuk mengiris bawang merah.

Diameter piringan pisau: $264 \mathrm{~mm}=0,264$ $\mathrm{m}$

Jari-jari piringan pisau: $132 \mathrm{~mm}=0,132 \mathrm{~m}$

Tebal piringan pisau $\quad: 10 \mathrm{~mm}$

Massa jenis aluminium $: 2,7 \mathrm{~kg} / \mathrm{liter}$

1) Volume piringan (V) $=\pi r^{2} \times$ Tebal piringan pisau

$=3,14 \times 132^{2} \mathrm{~mm} \times 10 \mathrm{~mm}=547113,6$ $\mathrm{mm}^{3}=0,55$ liter

2) Massa (m) =Massa jenis aluminium $\mathrm{x} \mathrm{V}$
$=2,7 \mathrm{~kg} / \mathrm{liter} \times 0,55$ liter

$=1,48 \mathrm{~kg}$

3) Gaya pada pisau $(F)$

$\mathrm{F}=\mathrm{m} \cdot \mathrm{g}$

$=1,48 \mathrm{~kg} \times 10 \mathrm{~m} / \mathrm{s}^{2}$

$=14,8 \mathrm{~N}$

4) Torsi yang bekerja pada pisau (T)

$\mathrm{T}=\mathrm{F} \cdot \mathrm{r}$

$=14,8 \mathrm{~N} \times 0,132 \mathrm{~m}$

$=1,95 \mathrm{Nm}$

5) Daya yang dibutuhkan untuk menggerakan pisau (P)

$$
\begin{aligned}
& P=\frac{2 \pi n T}{60} \\
& =\frac{2 \times 3,14 \times 431 \mathrm{rpm} \times 1,95 \mathrm{Nm}}{60} \\
& =87,97 \mathrm{Watt} \\
& =0,118 \mathrm{Hp}(1 \mathrm{Watt}=0,00134 \mathrm{Hp}) \\
& \text { Oleh karena itu dipilih dengan }
\end{aligned}
$$
menggunakan tenaga motor listrik dengan daya sebesar $0,25 \mathrm{Hp}$.

6) Analisis Perhitungan Pulley dan V-Belt

Daya motor listrik: 0,25 Hp

Putaran motor $\left(\mathrm{n}_{1}\right): 1400 \mathrm{rpm}$

Diameter pulley motor $\left(\mathrm{D}_{1}\right): 50,8 \mathrm{~mm}$

Diameter pulley piringan $\left(\mathrm{D}_{2}\right): 165,1 \mathrm{~mm}$

Jarak antar sumbu poros (x): $210 \mathrm{~mm}$

a.Putaran piringan pisau $\left(\mathrm{n}_{2}\right)=\frac{\mathrm{n}_{1} \times \mathrm{D}_{1}}{\mathrm{D}_{2}}$

$$
=\frac{1400 \mathrm{rpm} \times 50,8 \mathrm{~mm}}{165,1 \mathrm{~mm}}
$$

$=431 \mathrm{rpm}$

b. Panjang sabuk (L)

$$
L=\pi\left(r_{1}+r_{2}\right)+2 x+\left\{\frac{\left(r_{1}-r_{2}\right)^{2}}{x}\right\}
$$

$=3,14(25,4 \mathrm{~mm}+82,55 \mathrm{~mm})+2(210$

$\mathrm{mm})+\frac{(25,4 \mathrm{~mm}-82,5 \mathrm{~mm})}{210 \mathrm{~mm}}$

$=339 \mathrm{~mm}+420 \mathrm{~mm}+15,53 \mathrm{~mm}$

$=774,53 \mathrm{~mm}$

$=30$ inchi $(1 \mathrm{~mm}=0,0394$ inchi $)$

Jadi $V$-belt untuk sistem transmisi alat pemotong bawang merah ini adalah $\mathrm{V}$ belt tipe A-30.

\section{B. Pembahasan}

\section{Alat Pengiris Bawang Merah}

Alat pengiris bawang merah adalah alat yang dirancang untuk mengiris bawang merah dengan menggunakan alat tenaga penggerak motor listrik. Alat 
pengris bawang merah dapat dilihat pada Gambar.

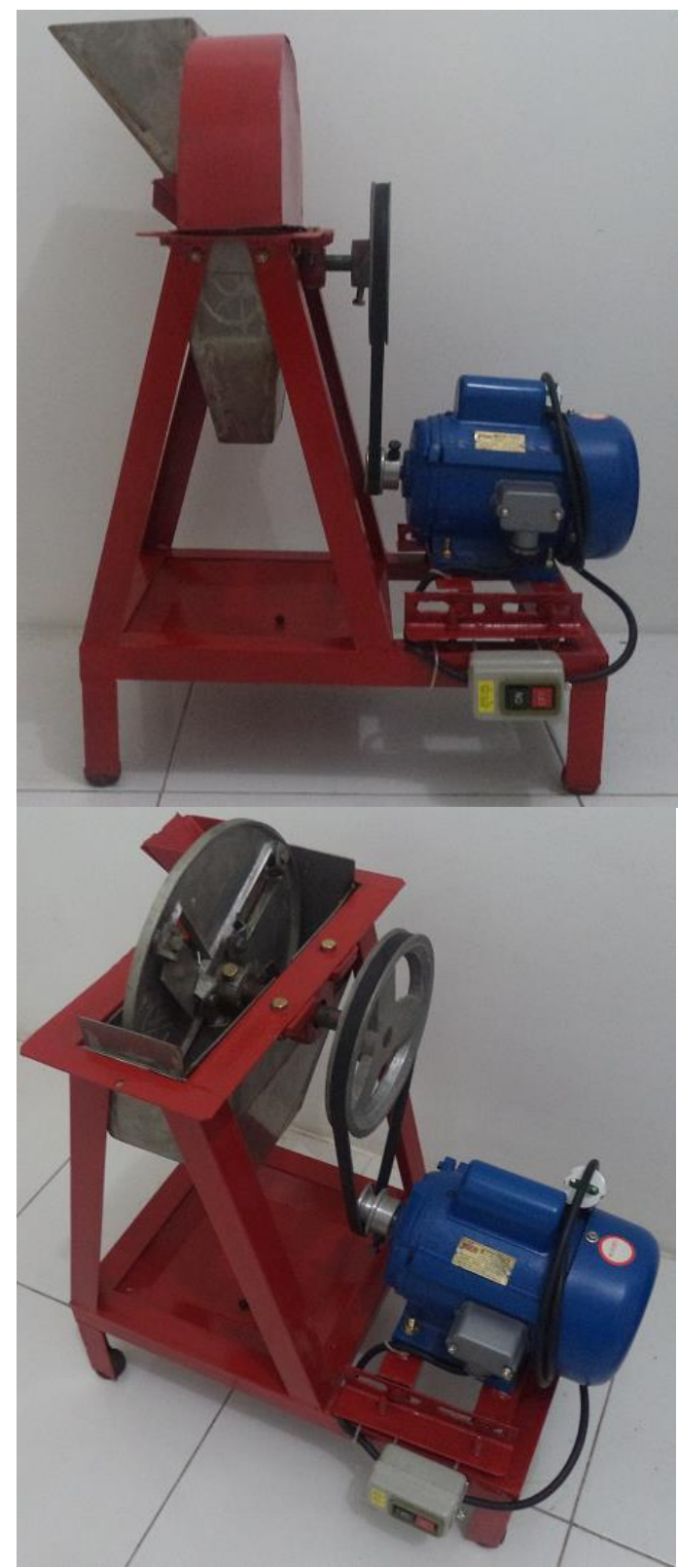

Gambar 3. Alat Pengiris Bawang Merah

Tabel 1. Spesifikasi Alat Pengiris Bawang Merah

\begin{tabular}{|l|l|}
\hline \multicolumn{1}{|c|}{ Spesifikasi } & \multicolumn{1}{c|}{ Uraian } \\
\hline Dimensi & \\
\hline Panjang & $500 \mathrm{~mm}$ \\
\hline Lebar & $355 \mathrm{~mm}$ \\
\hline Tinggi & $760 \mathrm{~mm}$ \\
\hline Kecepatan Putaran Pisau & $431 \mathrm{rpm}$ \\
\hline Kapasitas Alat & $46 \mathrm{Kg} / \mathrm{Jam}$ \\
\hline Ukuran Ketebalan Irisan & $1-1.5 \mathrm{~mm}$ \\
\hline Daya Motor & $1400 \mathrm{rpm}(0.25 \mathrm{Hp})$ \\
\hline
\end{tabular}

1) Prinsip Kerja Alat Pengiris Bawang Merah

Prinsip kerja alat pengiris bawang merah ini dengan menggunakan rotor berpisau dengan penggerak motor listrik. Bawang yang sudah dikupas kulitnya dimasukkan ke dalam Hopper Input kemuadian piringan yang punggungnya terdapat pisau, akan berputar karena digerakkan oleh motor listrik. Bawang merah akan teriris oleh pisau pengiris dan bawang yang telah teriris akan keluar melalui Hopper Output pengeluaran.

\section{2) Kapasitas Efektif Alat Pengiris Bawang} Merah

Kapasitas efektif alat didefenisikan sebagai kemampuan alat dan mesin dalam menghasilkan suatu produk $(\mathrm{kg})$ persatuan waktu (jam). Dalam hal ini kapasitas efektif alat dihitung dari perbandingan antara banyaknya bawang yang diiris $(\mathrm{kg})$ dengan waktu yang dibutuhkan selama proses pengirisan. Percobaan dilakukan dengan tiga metode, yaitu:

1. Bawang Merah dituang ke Hopper Input secara bertahap dan continued.

2. Bawang Merah dituang ke Hopper Input secara langsung.

3. Bawang Merah dituang ke Hopper Input secara langsung dan dibantu menggunakan penyodok.

Tabel 2. Kapasitas Alat dengan Metode 1

\begin{tabular}{|c|c|c|c|c|}
\hline $\begin{array}{c}\text { Percob } \\
\text { aan }\end{array}$ & $\begin{array}{c}\text { Berat } \\
\text { setelah } \\
\text { diiris } \\
\text { (kg) }\end{array}$ & $\begin{array}{c}\text { Waktu } \\
\text { pengiris } \\
\text { an } \\
\text { (detik) }\end{array}$ & $\begin{array}{c}\text { Waktu } \\
\text { pengiris } \\
\text { an (Jam) }\end{array}$ & $\begin{array}{c}\text { Kapasitas } \\
\text { efektif } \\
\text { alat } \\
(\text { Kg/Jam) }\end{array}$ \\
\hline I & 0,97 & 58,20 & 0,016 & 60,00 \\
\hline II & 0,98 & 58,54 & 0,016 & 60,27 \\
\hline III & 0,98 & 59,34 & 0,016 & 59,45 \\
\hline Rataan & 0,98 & 58,69 & 0,016 & 59,91 \\
\hline
\end{tabular}




\begin{tabular}{|c|c|c|c|c|}
\hline $\begin{array}{c}\text { Perco } \\
\text { baan }\end{array}$ & $\begin{array}{c}\text { Berat } \\
\text { setelah } \\
\text { diiris } \\
(\mathrm{kg})\end{array}$ & $\begin{array}{c}\text { Waktu } \\
\text { pengiris } \\
\text { an } \\
(\text { detik })\end{array}$ & $\begin{array}{c}\text { Waktu } \\
\text { pengiris } \\
\text { an (Jam) }\end{array}$ & $\begin{array}{c}\text { Kapasitas } \\
\text { efektif } \\
\text { Alat } \\
(\text { Kg/Jam) }\end{array}$ \\
\hline I & 0.99 & 59 & 0.016 & 60.10 \\
\hline II & 0.98 & 58 & 0.016 & 60.83 \\
\hline III & 0.97 & 58 & 0.016 & 60.21 \\
\hline $\begin{array}{c}\text { Rataa } \\
\mathrm{n}\end{array}$ & 0.98 & 58.43 & 0.016 & 60.38 \\
\hline
\end{tabular}

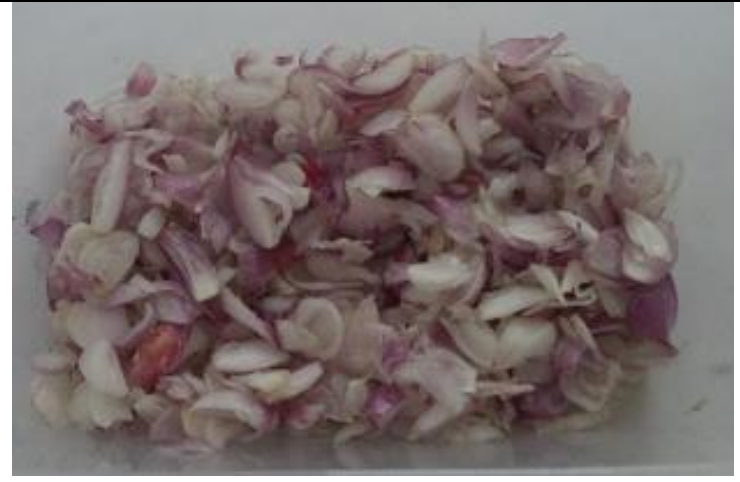

Gambar 4. Hasil irisan percobaan dengan metode 1

Tabel 3. Kapasitas Alat dengan Metode 2

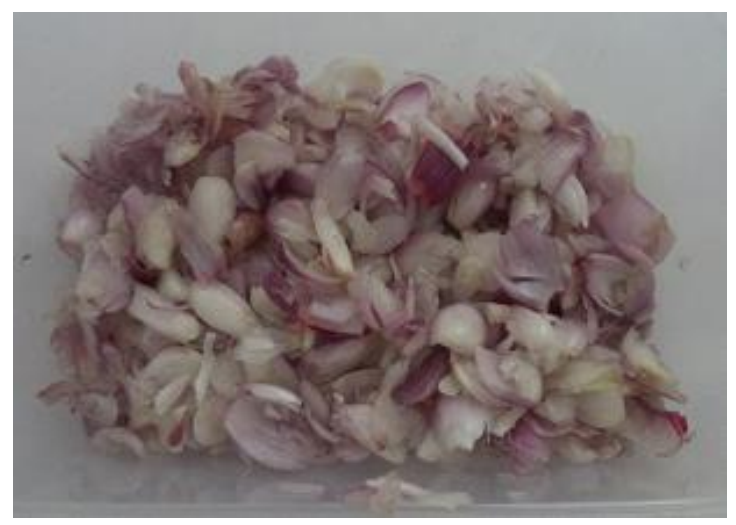

Gambar 5. Hasil irisan percobaan dengan metode 2
Tabel 4. Kapasitas Alat dengan Metode 3

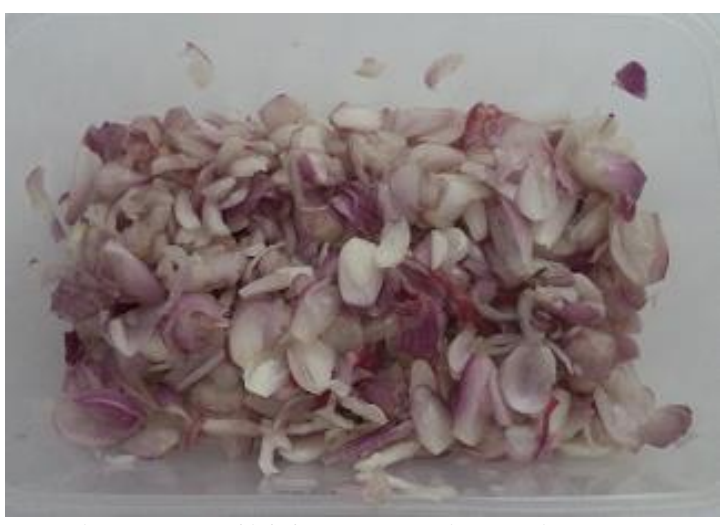

Gambar 6. Hasil irisan percobaan dengan

\begin{tabular}{|c|c|c|c|c|}
\hline $\begin{array}{c}\text { Perco } \\
\text { baan }\end{array}$ & $\begin{array}{c}\text { Berat } \\
\text { setelah } \\
\text { diiris } \\
(\mathrm{kg})\end{array}$ & $\begin{array}{c}\text { Waktu } \\
\text { pengiris } \\
\text { an } \\
\text { (detik) }\end{array}$ & $\begin{array}{c}\text { Waktu } \\
\text { pengiris } \\
\text { an (Jam) }\end{array}$ & $\begin{array}{c}\text { Kapasitas } \\
\text { efektif } \\
\text { Alat } \\
(\text { Kg/Jam })\end{array}$ \\
\hline I & 0.98 & 210 & 0.058 & 16.80 \\
\hline II & 0.97 & 225 & 0.063 & 15.52 \\
\hline III & 0.97 & 212 & 0.059 & 16.47 \\
\hline $\begin{array}{c}\text { Rataa } \\
\mathrm{n}\end{array}$ & 0.97 & 215.67 & 0.060 & 16.26 \\
\hline
\end{tabular}

metode 3

Dari percobaan yang dilakukan diperoleh kapasitas efektif alat pengiris bawang merah dengan metode 1 yaitu 59,91 $\mathrm{Kg} / \mathrm{Jam}$, metode 2 yaitu $16,26 \mathrm{Kg} / \mathrm{Jam}$ dan metode 3 yaitu 60,38 Kg/Jam. Dari hasil ini diperoleh kapasitas efektif alat sebesar 45,52 $\mathrm{Kg} / \mathrm{Jam}$.

\section{KESIMPULAN}

a. Alat pengiris Bawang Merah membutuhkan daya dari motor listrik sebesar 0,118 Hp, karena di pasaran tidak tersedia motor dengan daya tersebut maka digunakan motor dengan daya $0,25 \mathrm{Hp}$. Sistem transmisi alat pengiris bawang ini mengubah putaran motor listrik dari 1400 rpm menjadi $431 \mathrm{rpm}$, dengan komponen berupa 2 pulley, diameter $50,8 \mathrm{~mm}$ dan $165,1 \mathrm{~mm}$ dan dihubungkan oleh $V$-belt type A-30.

b. Prinsip kerja alat pengiris Bawang Merah ini sangatlah sederhana, menggunakan piringan berpisau dengan pengerak motor 
listrik yang akan berputar dan mengiris Bawang Merah.

c. Kapasitas efektif alat pengiris Bawang Merah ini adalah $46 \mathrm{Kg} / \mathrm{Jam}$, dengan tebal irisan 1-1,5 mm.

d. Perawatan alat pengiris bawang merah ini sangat mudah, baik perawatan secara rutin maupun periodik.

\section{DAFTAR NOTASI}

$P \quad=$ Daya $($ Watt $)$

$\mathrm{T}=$ Torsi (N.m)

$\mathrm{n} \quad=$ Putaran Poros $(\mathrm{Rpm})$

$\mathrm{F} \quad=$ Gaya $\left(\mathrm{N}\right.$ atau $\left.\mathrm{Kg} \cdot \mathrm{m} / \mathrm{s}^{2}\right)$

$\mathrm{m} \quad=$ Massa $(\mathrm{Kg})$

$\mathrm{g} \quad=$ Percepatan Gravitasi $\left(10 \mathrm{~m} / \mathrm{s}^{2}\right)$

$\mathrm{W}=$ Berat $\left(\mathrm{N}\right.$ atau Kg.m/s $\left./ \mathrm{s}^{2}\right)$

$\mathrm{R}=$ Jarak Terhadap Sumbu (m)

$\mathrm{D}_{2} \quad=$ Diameter Pulley yang Digerakkan (mm)

$\mathrm{D}_{1} \quad=$ Diameter Pulley Penggerak $(\mathrm{mm})$

$\mathrm{n}_{1} \quad=$ Putaran Pulley Penggerak $(\mathrm{Rpm})$

$\mathrm{n}_{2} \quad=$ Putaran Pulley yang Digerakkan

(Rpm)

$\mathrm{L} \quad=$ Panjang Sabuk $(\mathrm{mm})$

$\mathrm{X}=$ Jarak Sumbu Poros (mm)

$\mathrm{r}_{1} \quad=$ Jari-Jari Pulley Penggerak $(\mathrm{mm})$

$\mathrm{r}_{2} \quad=$ Jari-Jari Pulley yang Digerakkan (mm)

\section{DAFTAR PUSTAKA}

Ginting, R. (2010). Perancangan Produk. Yogyakarta: Graha Ilmu.

Khurmi, R.S., Gupta, J.K., Chand, S. (2005). Textbook of Machine Design, S.I. Units. Eurasia Publishing House (Pvt) Ltd, New Delhi, India

Lumbantobing, A. (2014). Rancang Bangun Alat Pengiris Bawang Mekanis. Suamtera Utara : Universitas Sumatera Utara.

Palgunadi, B. (2008). Desain Produk AspekAspek Desain. Bandung: ITB.

Suga, K. \& Sularso. (1991). Dasar Perancangan dan Pemilihan Element Mesin. Jakarta: PT. Pradnya Paramita.

Trianto. (2015). Rancang Bangun Mesin Pengiris Bawang (Transmisi). Solo : Universitas Sebelas Maret.
Taufik, Y., 2009, Effisiensi Pengirisan Bawang Merah Dengan Variasi Sudut Kemiringan Pisau Pada Alat Pengiris Bawang Merah Tipe Pengiris Vertikal, Vol. 11 No. 3, September 2009, pp. 157172.

Widiabtara, T., 2010, Rancang Bangun Alat Pengiris Bawang Merah Dengan Pengiris Vertikal (Shallot Slicer), ISSN: 1411-4216, pp. F-01-1-7. 